\title{
A higher level of human papillomavirus 16 DNA was associated with an increased risk for cervical carcinoma in situ
}

Josefsson AM, Magnusson PK, Ylitalo N, et al. Viral load of human papilloma virus 16 as a determinant for development of cervical carcinoma in situ: a nested case-control study. Lancet 2000 Jun 24;355:2189-93.

QUESTION: In women with a first normal cervical smear during screening, what is the association between human papillomavirus (HPV) DNA levels and development of cervical carcinoma in situ (CIS)?

Design

Nested case control study of women in a screening programme from 1969 to 1995.

\section{Setting}

Uppsala County, Sweden.

\section{Participants}

Women who were $<50$ years of age at entry, were born in Sweden, and had a normal first cervical smear and smears that contained genomic DNA as measured by $\beta$ actin. The case group consisted of 478 women (2081 smears). 5 women in the control group were matched to each woman with CIS by date of entry to the cohort, age, and time of first smear. Women in the control group had to be alive without developing CIS or invasive cervical cancer or having a hysterectomy before the date of diagnosis for their matched case; when only 1 smear was available for a woman randomly selected from the original pool of women in the control group, a second matched woman from the control group was randomly selected $(\mathrm{n}=608[478$ first controls and 130 second controls], 1754 smears).

\section{Assessment of risk factors}

The level of HPV-16 DNA was estimated by using quantitative polymerase chain reaction ( $5^{\prime}$ exonuclease [Taqman] method). To adjust for different levels of genomic DNA, a nuclear gene ( $\beta$ actin) was assessed.

\section{Main outcome measures}

Data on women with CIS were obtained from the National Cancer Registry. An experienced pathologist reassessed the histological samples to confirm the diagnosis.

\section{Main results}

871 smears (42\%) from women with CIS and 117 smears (7\%) from the control group were positive for HPV-16. After adjustment for level of $\beta$ actin, a greater mean level of HPV-16 DNA was associated with an increased risk for CIS (table). A similar relation existed when only the first smear was included in the analysis.

\section{Conclusion}

In women who had a first normal cervical smear in a screening programme, a higher mean level of HPV-16 DNA was associated with an increased risk for cervical carcinoma in situ.

Associations between concentrations of human papillomavirus (HPV) 16 DNA and risk for cervical cancer

\begin{tabular}{ll}
$\begin{array}{l}\text { Quintiles of mean HPV } 16 \text { threshold } \\
\text { cycle number }\left(\mathrm{C}_{\mathrm{t}}\right)^{*}\end{array}$ & $\begin{array}{c}\text { Adjusted odds } \\
\text { ratio }(95 \% \mathrm{Cl})+\end{array}$ \\
\hline HPV 16 negative & 1.0 \\
\hline HPV 16 positive, $\mathrm{C}_{\mathrm{t}}$ value 44.8 to 50.0 & $2.0(1.1$ to 3.8$)$ \\
\hline HPV 16 positive, $\mathrm{C}_{\mathrm{t}}$ value 41.25 to 44.8 & $4.4(2.3$ to 8.3$)$ \\
\hline HPV 16 positive, $\mathrm{C}_{\mathrm{t}}$ value 38.99 to 41.25 & $8.1(3.8$ to 17.3$)$ \\
\hline HPV 16 positive, $\mathrm{C}_{\mathrm{t}}$ value 36.66 to 38.99 & $18.7(7.1$ to 49.5$)$ \\
\hline HPV 16 positive, $\mathrm{C}_{\mathrm{t}}$ value $<36.66$ & $68.8(15.8$ to 299.6$)$ \\
\hline
\end{tabular}

*Lower values of $C_{t}$ denote higher concentrations of HPV 16 DNA. †Odds ratio adjusted for level of $\beta$ actin.

\section{COMMENTARY}

Infection with HPV type 16 or 18 has been associated with a higher rate of progression of cervical squamous intraepithelial lesions (SILs) and cancer. ${ }^{1}$ The ability to identify patients with oncogenic HPV types might lead to improved detection of women who are more likely to develop high grade cervical SILs and cancer. This improved detection could affect management decisions for women with low grade cytological abnormalities. Currently available commercial tests identify the presence of high risk HPV types. Despite the potential value of this technology, recent reports suggest a lack of utility for these qualitative tests in women with low grade cervical SILs. The Atypical Squamous Cells of Undetermined Significance/Low-Grade Squamous Epithelial Lesions Triage Study (ALTS) is a large randomised trial of women with recently detected atypical squamous cells of undetermined significance and low grade cervical SILs. High risk HPV DNA was detected in $82.9 \%$ of women with low grade cervical SILs, therefore limiting the usefulness of measuring it. Results of the ALTS study for women with atypical squamous cells of undetermined significance are pending. ${ }^{2}$ Manos $e t$ al studied HPV testing combined with ThinPrep in women with atypical squamous cells of undetermined significance and found that the HPV test had a sensitivity of $89.2 \%$ and a specificity of $64.1 \%{ }^{3}$ Other studies have shown sensitivities $\geqslant 90 \%$ for the second generation, qualitative, high risk HPV test ${ }^{4}$, however, its false positive rate ranged from $5 \%$ to $20 \%$.

Josefsson et al did a nested case control study on cervical smears of women who developed cervical CIS and those who did not. They measured HPV-16 viral load on archived cervical smears using a quantitative polymerase chain reaction assay available only in research laboratories. They found a strong positive relation between viral load and risk for cervical CIS, but only 283 of 495 women with CIS had any HPV-16 DNA; of those, only 110 women had viral loads in the top 2 quintiles. In the second study based on the same cohort, the time from high HPV-16 viral load to appearance of CIS was determined: a mean time of 17 years. The role for HPV testing in screening for precancerous changes of the cervix remains to be defined. Ultimately, commercially available tests that measure high risk HPV viral load might allow increases in screening intervals for women who test negative. To date, HPV testing has not provided the ability to triage women accurately into high risk and low risk groups. The studies by Josefsson and Ylitalo and their colleagues make some progress toward this goal; however, it is critical to remember that nearly one half of the women with CIS were negative for HPV-16 in their sample. A successful triage would need to measure viral load for several types of high risk HPV. 